Research Article

\title{
Frequency of Hypothyroidism in Patients with Hepatitis C on Standard Interferon Therapy
}

\author{
Aijaz Zeeshan Khan Chachar ${ }^{1, *}$, Khalid Mahmood Anjum ${ }^{2}$, Arzinda Fatima ${ }^{1}$, Nauman Tarif ${ }^{1}$, \\ Saleema Qaisera $^{3}$, Javed Iqbal ${ }^{4}$ and Hafiz Muhammad Ahsan Khan ${ }^{2}$ \\ ${ }^{1}$ Fatima Memorial Hospital, Lahore, Pakistan. \\ ${ }^{2}$ FMH College of Medicine and Dentistry, Lahore, Pakistan. \\ ${ }^{3}$ Nephrology, Fatima Memorial Hospital, Lahore, Pakistan. \\ ${ }^{4}$ Virtual University, Pakistan.
}

\begin{abstract}
Introduction: Hepatitis C virus (HCV) infection is an emerging public health issue affecting young people in developing countries. It is the common cause of chronic liver disease which if untreated, leads to cirrhosis, hepatocellular carcinoma and ultimately liver transplantation. HCV infection is conventionally treated with Interferon- $\alpha$ (IFN- $\alpha$ ) and anti-viral Ribavirin (RBV). Thyroid dysfunction is frequently encountered in patients having HCV and being treated with IFN- $\alpha$ and antiviral (RBV).
\end{abstract}

Objective: To find out the incidence of thyroid dysfunction i.e., hypothyroidism in patients of HCV infection being treated with IFN- $\alpha$ and anti-viral (RBV).

Material and Methods: 250 patients having HCV infection were enrolled for the study. All patients were treated with 3 million units subcontinually 3 times per week and antiviral (RBV). Thyroid function tests were performed at the start of the treatment to have a baseline thyroid status and at the end of the treatment. Patients were considered to have hypothyroidism when thyroid stimulating hormone (TSH) was more than $4.0 \mathrm{mIU} / \mathrm{L}$.

Results: 47 (18.8\%) patients had thyroid dysfunction after 3 months of the therapy. Out of these 47 patients, 36 (76.59\%) had hypothyroidism and $11(23.4 \%)$ had hyperthyroidism. It is evident that patients on IFN- $\alpha$ and antiviral therapy for HCV infection developed thyroid dysfunction particularly hypothyroidism that is more in females.

Keywords: Hepatitis C virus, Hypothyroidism, Standard interferon therapy.

doi.org/10.21089/njhs.22.0057

\section{BACKGROUND}

HCV infection is an emerging health problem in most countries and 366000 patients die annually worldwide due to Hepatitis C. If the treatment is delayed it leads to chronic $\mathrm{HCV}$ infection, $\mathrm{HCV}$ induced cirrhosis, liver failure and Hepatocellular Carcinoma (HCC). There are many thyroid diseases linked to chronic hepatitis $\mathrm{C}$.

Around 3 out of 10 people have HCV infection in Pakistan and its prevalence is $2.3 \%$ in children, $5.2 \%$ in pregnant women, $5.3 \%$ in general population, $3.1 \%$ in army recruits, $3.6 \%$ in blood donors, $5.4 \%$ in health care workers, $10.3 \%$ have high risk, $12 \%$ have provisional diagnosis of $\mathrm{HCV}$ infection and out of all these 54\% have chronic HCV infection [1].

*Address correspondence to this author at the Fatima Memorial Hospital, Lahore, Pakistan. E-mail: dr_aijaz84@ hotmail.com

(C) 2017 NiBD Publicatons
IFN- $\alpha$ mostly cause thyroiditis, which can be grouped as autoimmune or non-autoimmune IFN induced thyroiditis (IIT). Subclinical thyroiditis is seen in $20-40 \%$ and clinically evident thyroiditis in 5-10\% of patients. Autoimmune IIT also known as Hashimoto's thyroiditis, is characterized by the production of or worsening of antithyroid antibody levels with or without hypothyroidism. Non-autoimmune IIT presents as destructive thyroiditis and hypothyroidism [2].

Great successes of IFN- $\alpha$ as a therapeutic agent has been accepted in the treatment of chronic hepatitis C. IFN- $\alpha$ and RBV if used together, cures up to $50 \%-70 \%$ of patients [3].

However, IFN- $\alpha$ therapy has its own side effects, which may result in complications and significant morbidity if the therapy is stopped [4]. Ward et al. conducted a study in 2001 and found that 3 to $14 \%$ patients had thyroid dysfunction [5]. Bini et al. in 2004 concluded that $10.7 \%$ patients had thyroid dysfunction and $8 \%$ of the patients having $\mathrm{HCV}$ infection had hypothyroidism who were taking IFN therapy [6]. 
Foldes et al., in 2004, enrolled $138 \mathrm{HCV}$ patients to see the thyroid dysfunction, $21.7 \%$ patients had thyroid dysfunction and out of these patients $8.7 \%$ patients had hypothyroidism [7]. Kee et al., (2006) concluded that $12.6 \%$ patients had thyroid dysfunction [8]. Vezali et al., concluded that $21.3 \%$ patients had thyroid dysfunction out of these patients, $18 \%$ had hypothyroidism [9]. Nadeem et al., conducted a study in 2010 and suggested to reduce the dose of IFN therapy if any thyroid dysfunction develops [10]. Yan et al., studied the potential impact of thyroid dysfunction due to interferon therapy and reported that $11.5 \%$ patients had thyroid dysfunction, out of which $6.4 \%$ patients had hypothyroidism on IFN therapy [11].

A number of studies had been conducted to see the percentage of hepatitis $\mathrm{C}$ patients who developed hypothyroidism due to IFN therapy all over the world but sufficient data is lacking in Pakistan on this particular topic. It is the need of the day that patients need to be detected earlier and the IFN therapy should be optimized in order to reduce the complications.

\section{OBJECTIVE OF STUDY}

To explore the incidence rate of hypothyroidism among hepatitis $\mathrm{C}$ patients who are taking standard interferon therapy and anti-viral (RBV).

\section{MATERIAL AND METHODS}

This study was conducted at outpatient department of medicine, Fatima Memorial Hospital Lahore and its design was considered as descriptive case series. 250 patients were enrolled by calculating sample size under $95 \%$ confidence level, 5\% margin of error and $18 \%$ as percentage of thyroid dysfunction who had HCV infection and were taking standard IFN therapy. Duration of the study was 6 months and purposive sampling technique was adapted. Those HCV patients were selected whose age fell between 10 to 70 years and patients having serum TSH level of $>4.0 \mathrm{mlU} / \mathrm{L}$ were considered to have hypothyroidism. Patients who had alanine transaminase (ALT) $>40$ IU/L, decompensated chronic liver disease (DCLD), thyroid disorder, getting amiodarone therapy, ejection fraction (EF) $<30 \%$ and creatinine of $>5 \mathrm{mg} / \mathrm{dl}$. Patients on thyroid treatment, co-infection with human immunodeficiency virus (HIV) or hepatitis B virus (HBV), pregnancy, lactation, serious medical conditions like malignancy, severe cardiopulmonary disease and uncontrolled diabetes mellitus were excluded from the study. Simultaneously all those patients were excluded who were on drugs like lithium, amiodarone and iodine preparations and those who had radiation history because all these factors can alter the levels of thyroid hormone. HCV antibodies were detected using third generation commercial enzyme-linked immune sorbent assay (ELISA). The HCV Ribonucleic acid (RNA) load was also measured. Thyroid function tests, including serum thyrotropin (thyroid-stimulating hormone
[TSH]), free thyroxine (FT4), and free triiodothyronine (FT3) were performed by an ultrasensitive immune chemiluminescent non-competitive assay. Thyroid disease was defined as any value of these markers (TSH, FT3, and FT4), which was greater or less than the normal values. The reference range (RR) for TSH was $0.20-4 \mathrm{mIU} / \mathrm{Ls}$, FT4 0.61$1.12 \mathrm{ng} / \mathrm{dl}$ and FT3 2.5-3.90 pg/ml.

\section{DATA COLLECTION AND ANALYSIS}

A total of 250 patients were enrolled with written and informed consent, who met the inclusion criteria and visited outpatient department (OPD) of Medicine of Fatima Memorial hospital Lahore. Three cc blood was taken for TSH before and after three months of IFN therapy. Value of TSH between $0.20-0.4 \mathrm{mlU} / \mathrm{L}$ was considered as normal. Data was analyzed using SPSS version 22. Mean and standard deviation was calculated for quantitative variables and frequency with percentages was reported for qualitative variables.

\section{RESULTS}

According to the study, mean \pm standard deviation (SD) age of patients was $37.39 \pm 8.4$ years. There were 42 (16.8\%) patients having age $\leq 25$ years, $70(28 \%)$ patients fell in the age range of 26-35 years, 107 (42.8\%) patients fell in the age range 36-45 years, $25(10 \%)$ patients had age range 46-55 years whereas $6(2.4 \%)$ patients in age range of equal or more than 56 years. $154(61.6 \%)$ male and $96(38.4 \%)$ female patients participated in the study. (Table $\mathbf{1}$ )

Mean \pm SD of thyroid stimulating hormone (TSH) of the patients was $1.75 \pm 1.6 \mathrm{mIU} / \mathrm{L}$. There was $1(0.4 \%)$ patient having TSH range $\leq 0.05,9(3.6 \%)$ patients fell in TSH range of $0.06-0.20 \mathrm{mIU} / \mathrm{L}, 177(70.8 \%)$ patients fell in TSH range of $0.21-2.00 \mathrm{mIU} / \mathrm{L}, 27(10.8 \%)$ patients fell in TSH range of $2.01-4.00 \mathrm{mIU} / \mathrm{L}, 27(10.8 \%)$ patients fell in TSH range of $4.01-6.00 \mathrm{mIU} / \mathrm{L}$ and $9(3.6 \%)$ patients fell in TSH range $\geq 6.01 \mathrm{mIU} / \mathrm{L}$. (Table 2).

Among the 250 patients, $47(18.8 \%)$ were having thyroid dysfunction while 203 patients $(81.2 \%)$ did not have thyroid dysfunction at third month of IFN therapy. Out of 47 patients, $14(29.78 \%)$ male and $33(70.22 \%)$ female patients had thyroid dysfunction. (Table $\mathbf{3}$ ).

Complete thyroid status after 3 months therapy showed that $203(81.2 \%)$ patients had euthyroid status, $36(14.4 \%)$ had hypothyroidism and $11(4.4 \%)$ patients had hyperthyroid, out of 36 hypothyroid patients; there were $10(4 \%)$ male patients and $26(10.4 \%)$ females patients. (Table 4).

Table 1. Mean \pm standard deviation (SD) age of patients.

\begin{tabular}{|c|c|c|}
\hline Characteristics & Mean & SD \\
\hline Age & 37.39 & 8.4 \\
\hline
\end{tabular}




\begin{tabular}{|c|c|c|}
\hline Age-Categories & Frequency & Percentage \\
\hline$\leq 25$ year & 42 & 16.8 \\
\hline $26-35$ year & 70 & 28 \\
\hline $36-45$ year & 107 & 42.8 \\
\hline $46-55$ year & 25 & 10 \\
\hline$\geq 56$ year & 6 & 2.4 \\
\hline Male & 154 & 61.6 \\
\hline Female & 96 & 38.4 \\
\hline
\end{tabular}

Table 2. Mean \pm SD of Thyroid Stimulating Hormone (TSH).

\begin{tabular}{|c|c|c|}
\hline Characteristics & Mean & SD \\
\hline TSH & 1.75 & 1.6 \\
\hline TSH-Range & Frequency & Percentage \\
\hline$\leq 0.05$ & 1 & 0.4 \\
\hline $0.06-0.20$ & 9 & 3.6 \\
\hline $0.21-2.00$ & 177 & 70.8 \\
\hline $2.01-4.00$ & 27 & 10.8 \\
\hline $4.01-6.00$ & 27 & 10.8 \\
\hline$\geq 6.01$ & 9 & 3.6 \\
\hline
\end{tabular}

Table 3. Thyroid dysfunction of IFN therapy.

\begin{tabular}{|c|c|c|}
\hline $\begin{array}{c}\text { Thyroid Dysfunction at } 3^{\text {rd }} \text { Month of } \\
\text { IFN Therapy }\end{array}$ & Frequency & Percentage \\
\hline Yes & 47 & 18.8 \\
\hline No & 203 & 81.2 \\
\hline
\end{tabular}

Table 4. Thyroid Status at of IFN therapy.

\begin{tabular}{|c|c|c|}
\hline $\begin{array}{c}\text { Thyroid Status at } \mathbf{3}^{\text {rd }} \text { Month of IFN } \\
\text { Therapy }\end{array}$ & Frequency & Percentage \\
\hline Euthyroid & 203 & 81.2 \\
\hline Hypothyroid & 36 & 14.4 \\
\hline Hyperthyroid & 11 & 4.4 \\
\hline
\end{tabular}

\section{DISCUSSION}

Hepatitis C, a chronic infection, is a worldwide concern that affects up to $80 \%$ of the infected subjects [12]. Prevalence of $\mathrm{HCV}$ is $1.6 \%$ in both United States and Pakistan. Conven-

tionally, IFN- $\alpha$ therapy is frequently been used. To treat the IFN- $\alpha$ infection, is one of the group of cytokines with antiviral, anti-proliferative, and immune-modulatory properties. In cases of hepatitis $\mathrm{C}$, the presence of moderate to severe necro-inflammatory activity intimates the use of IFN.

IFN- $\alpha$ is well documented to be associated with thyroid dysfunction. It has a direct inhibitory effect on thyroid gland and results in decreased thyroid hormone secretion; immunestimulation (in the presence of hepatitis $\mathrm{C}$ infection), activation of lymphocytes and natural killer cells, increased production of tumor necrosis factor, IFN- $\alpha$, Interleukins and other cytokines and increased production of immuneglobulins [12]. All these factors lead to the development of thyroid auto-antibodies with destruction of the thyroid gland; leading to hypothyroidism. Hypothyroidism is an endocrine disorder manifested by deficiency of thyroid hormone.

Case reports and follow-up studies of large cohorts of patients on IFN therapy have reflected that immune-mediated complications are uncommon but still can occur in human body. IFN therapy can trigger immune-related dysfunctions and can provoke existing autoimmune tendency. There is no or weak association between severity of the disease and response to therapy with IFN-induced thyroid dysfunction. 13 (26\%) of the patients were found to develop hypothyroidism, and $1(2 \%)$ patient developed hyperthyroidism in the course of 12 weeks therapy [13]. It was observed that female patients $(10.4 \%)$ had relatively higher rate of developing hypothyroidism than male patients.

In a similar study, Goyal et al. (2016) concluded that $26 \%$ patients had hypothyroidism [13]. Ward et al. in 2001, Bini et al. in 2004, Foldes et al. in 2004, Vezali et al. in 2009 and Yan et al. in 2012, investigated that 3 to $14 \%, 10.7 \%, 8.7 \%$, $18 \%$ and $11.5 \%$ HCV patient on IFN- $\alpha$ and anti-viral (RBV) developed thyroid dysfunction respectively [5-7, 9, 11]. Kee et al. in 2006 concluded that approximately $2 \%$ patients had thyroid dysfunction on long term in small group of patients [8].

Mean and standard deviation of age of patients was $37.39 \pm$ 8.4 years which is comparable with the study of Vezali et al. (2009) 11 and Yan et al. (2012) [9, 11]. Mean thyroid stimulating hormone (TSH) level of the patients was $1.75+1.6$ $\mathrm{mIU} / \mathrm{L}$ but the study of Vezali et al. which (2009) shows mean of TSH for all patients to be $1.62 \pm 0.92 \mathrm{mIU} / \mathrm{L}$.

The study of Vezali et al. which was conducted in 2009, found that 13 (21.3\%) patients had thyroid dysfunction [9]. According to Foldes et al. (2004), the incidence of thyroid dysfunction was $21.7 \%$ [7]. In this study, 14 (29.78\%) males and $33(70.22 \%)$ female had thyroid dysfunction. Vezali et al. (2009) concluded that $4(30.8 \%)$ male and $9(69.2 \%)$ females patients; Yan et al. (2012) concluded that 21 (30.9\%) males and $47(69.1 \%)$ female patients suffered from thyroid dysfunction after IFN therapy $[9,11]$. 
$36(14.4 \%)$ patients suffered from hypothyroidism. Vezali et al. (2009) found $18 \%$ patients suffered from hypothyroidism, $3.3 \%$ had hyperthyroidism and $78.7 \%$ had euthyroid status [9]. Yan et al. (2012) investigated that $6.4 \%$ patients had hypothyroidism, $5.1 \%$ hyperthyroidism and $88.5 \%$ have euthyroid status [11]. Bini et al. (2004) concluded that $8 \%$ patients developed hypothyroidism, $2.7 \%$ had hyperthyroidism and $89.3 \%$ have euthyroid [6]. Foldes et al. (2004) concluded that $8.7 \%$ suffered from hypothyroidism [7]. It can be said that results of previous studies are comparable with results of this study as well.

\section{CONCLUSION}

HCV patients on IFN and antiviral therapy develop thyroid dysfunction, so these patients should be regularly screened for thyroid disorders as well as timely managed to maintain euthyroid status.

\section{RECOMMENDATION}

It is strongly recommended that patients on IFN therapy for $\mathrm{HCV}$ infection should closely be monitored at the baseline, in middle and at the end of treatment for any change in thyroid status so that prompt action can be taken at that time to minimize complications.

\section{LIMITATIONS}

As the prevalence of HCV infection is high in Pakistan and this was a single center study so results cannot be generalized to whole population. Further, large scale studies are required for detection of this problem.

\section{CONFLICT OF INTEREST}

Declared none.

\section{ACKNOWLEDGEMENT}

Aijaz Zeeshan Khan Chachar designed the study and wrote the final draft. Aijaz Zeeshan Khan Chachar and Arzinda Fatima collected the data. Khalid Mahmood Anjum analyzed the data, interpreted the results and wrote initial draft, NT and Saleema Qaisera reviewed the final manuscript. JI coded the data and helped in data entry in SPSS.

\section{REFERENCES}

[1] Wood A, Hoofnagle J, D Bisceglie, A. The treatment of chronic viral hepatitis. N. Engl. J. Med., 1997; 336(5):347-56. DOI: 10.1056/nejm199701303360507
[2] Pfeffer L, Dinarello C, Herberman R, Williams B, Borden E, Bordens $\mathrm{R}$, et al. Biological properties of recombinant alphainterferons: $40^{\text {th }}$ anniversary of the discovery of interferons. Cancer. Res., 1998; 58(12): 2489-2499.

[3] Fried M, Shiffman M, Reddy K, Smith C, Marinos G, Gonçales F, et al. Peginterferon alpha-2a plus ribavirin for chronic hepatitis C virus infection. N. Engl. J. Med., 2002; 347(13): 975-982. DOI: 10.1056/NEJMoa020047

[4] Russo M, Fried M. Side effects of therapy for chronic hepatitis C. Gastroenterology. 2003; 124(6): 1711-1719. DOI: 10.1016/s00165085(03)00394-9

[5] Ward D, Bing-You R. Autoimmune thyroid dysfunction induced by interferon-alpha treatment for chronic hepatitis $\mathrm{C}$ : screening and monitoring recommendations. Endocr. Pract., 2001; 7(1): 52-58. DOI: $10.4158 /$ ep.7.1.52

[6] Bini E, Mehandru S. Incidence of thyroid dysfunction during interferon-alpha $2 \mathrm{~b}$ and ribavirin therapy in men with chronic hepatitis C. Arch. Intern. Med., 2004; 164(21): 2371-2376. DOI: 10.1001/archinte. 164.21.2371

[7] Foldes I, Dávid K, Horváth G, Osztrogonácz H, Jankovics K, Tolvaj G. Thyroid dysfunctions in patients with viral hepatitis treated with interferon-alpha. Orv. Hetil., 2004; 145(23): 12111216.

[8] Kee K, Lee C, Wang J, Tung H, Changchien C, Lu S, et al. Thyroid dysfunction in patients with chronic hepatitis $\mathrm{C}$ receiving a combined therapy of interferon and ribavirin: incidence, associated factors and prognosis. J. Gastroenterol. Hepatol., 2006; 219(1p2): 319-326. DOI: 10.1111/j.1440-1746.2005.03947.x

[9] Vezali E, Elefsiniotis I, Mihas C, Konstantinou E, Saroglou J. Thyroid dysfunction in patients with chronic hepatitis C: virus- or therapy-related? J. Gastroenterol. Hepatol., 2009; 24(6): 1024-29. DOI: $10.1111 / \mathrm{j} .1440-1746.2009 .05812 . x$

[10] Nadeem A, Hussain M, Aslam M, Hussain T. Interferon-alpha induced and ribavirin induced thyroid dysfunction in patients with chronic hepatitis C. Hepat. Mon., 2010; 10(2): 132-140.

[11] Yan Z, Fan K, Fan Y, Wang X, Mao Q, Deng G, et al. Thyroid dysfunction in chinese patients with chronic hepatitis $\mathrm{C}$ treated with interferon-alpha: incidence, long-term outcomes and predictive factors. Hepat. Mon., 2012; 12(9): 6390. DOI: $10.5812 /$ hepatmon.6390

[12] Antonelli A, Ferri C, Fallahi P, Ferrari S, Ghinoi A, Rotondi M, et $a l$. Thyroid disorders in chronic hepatitis $\mathrm{C}$ virus infection. Thyroid. 2006; 16(6): 563-572. DOI:10.1089/thy.2006.16.563

[13] Goyal G, Panag K, Garg R. Prevalence of thyroid disorders in hepatitis $\mathrm{C}$ virus positive patients on interferon and antiviral therapy. Int. J. Appl. Basic. Med. Res., 2016; 6(4): 245-248. DOI: $10.4103 / 2229-516 x .192587$ 